
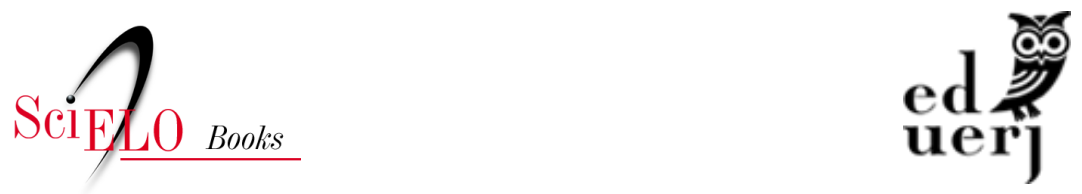

\title{
2. Simone Schwarz-Bart: breve biografia
}

\author{
Vanessa Massoni da Rocha
}

\section{SciELO Books / SciELO Livros / SciELO Libros}

ROCHA, V. M. Simone Schwarz-Bart: breve biografia. In: Tradução em (ent)revista: Simone Schwarz-Bart e as tradutoras brasileiras [online]. Rio de Janeiro: EDUERJ, 2021, pp. 21-31. Letras UERJ collection. ISBN: 978-65-9911115-0. https://doi.org/10.7476/9786599111150.0002.

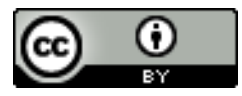

All the contents of this work, except where otherwise noted, is licensed under a Creative Commons Attribution 4.0 International license.

Todo o conteúdo deste trabalho, exceto quando houver ressalva, é publicado sob a licença Creative Commons Atribição 4.0.

Todo el contenido de esta obra, excepto donde se indique lo contrario, está bajo licencia de la licencia Creative Commons Reconocimento 4.0. 


\section{Simone Schwarz-Bart: breve biografia}

Simone Brumant, filha de uma professora e de um militar guadalupenses, nasce em 9 de dezembro de 1938 na pequena cidade de Saintes, localizada do departamento de Charente-Maritime, região da Nova Aquitânia, na parte oeste da França. Aos três anos, emigra para Pointe-à-Pitre, capital de Guadalupe, onde inicia sua formação escolar. Estuda igualmente em Paris e em Dakar. E, na idade adulta, mora ainda na Suíça. "Esta diáspora se refletirá em toda a sua escrita, explorando o triângulo imaginário África, Europa, Caribe", observa a professora e pesquisadora belga Kathleen Gyssels (1999), especialista na obra schwarz-bartiana. Aos 20 anos, Simone conhece o escritor André Schwarz-Bart na capital francesa. O encontro se dá de maneira fortuita, no dia 15 de maio de 1959: ela, perdida nas ruas da grande metrópole, na saída da estação de metrô Cardinal-Lemoine, e ele, procurando indicar-lhe algumas direções. Ele lhe perguntou timidamente: “'Você está perdida?', e em crioulo: 'você não é nem da Martinica, nem da Guiana, mas da Guadalupe"' (2019, p. 21). Foram tomar um café, que se prolongou das 
$14 \mathrm{~h}$ até às $23 \mathrm{~h}$, no qual ele revelou ter aprendido um pouco de crioulo com o amigo Édouard Glissant, prestigiado autor e crítico nascido na Ilha das Flores, a Martinica. A cena se descortina de maneira minuciosa no livro Nous navons pas vu passer les jours, de 2019, escrito a quatro mãos por Simone com o jornalista e biográfico Yann Plougastel.

Na véspera desse encontro, André havia entregado à editora o manuscrito do romance $O$ último dos justos, consagrado em 1959 com o prêmio Goncourt. Eles se casam cinco anos depois e têm dois filhos: Bernard e Jacques. Bernard, advogado, mora em Pointe-à-Pitre, e Jacques, renomado e premiado saxofonista de jazz, mora atualmente em Massachusetts, nos Estados Unidos. Simone adota, desde então, o sobrenome do marido: Szwarcbart. A grafia Schwarz-Bart surge por sugestão e influência da editora Seuil quando do lançamento do primeiro romance de André. Simone acolherá o mesmo nome artístico do marido.

Por iniciativa e insistência de André, Simone deixa de lado suas hesitações e ingressa no mundo literário graças ao projeto do Ciclo antilhano: escrita a quatro mãos, de seis volumes capazes de repertoriar a história antilhana entre 1760 e 1953, a partir da figura central da mulata ${ }^{1}$ escravizada Solitude ${ }^{2}$, personagem histórica de resistência

I No Brasil, no âmbito dos estudos decoloniais, evita-se o uso dos termos mulato/mulata, cuja origem aponta para a animalização dos seres escravizados. Termo pejorativo, ele faz alusão à origem impura da "mula", fruto da mestiçagem entre duas espécies distintas: cavalos e jumentos. A esse respeito, ver Djamila Ribeiro (2018, p. 99), e Grada Kilomba (2019, p. 79).

No âmbito antilhano, o termo possui maior aceitação e está presente de maneira flagrante no título do romance La mulâtresse Solitude, de André Schwarz-Bart, de 1972.

O reconhecimento da importância da personagem histórica Solitude pode ser observado em homenagens na forma de monumentos em espaços públicos. Para além de figurar em nome de estabelecimento de ensino em Pointe-à-Pitre, capital da Guadalupe, e em nome de rua em Pointe-à Pitre e Ivry-Sur-Seine, sul de Paris, em 20I4, Solitude foi retratada em estátuas. A primeira e a mais conhecida foi erigida em Pointe-à-Pitre em 1999 por Jacky Poulier. Trata-se de uma representação de Solitude no final da gravidez, com barriga proeminente, rosto altivo, braços dobrados e apoiados nas ancas. Em 2007, Nicolas Alquin criou uma estátua de madeira e metal disposta em Marie-Galante, uma das ilhas que compõe o arquipélago de Guadalupe. Nesta 
à escravidão. Aproveitando-se do prestígio conquistado pelo prêmio Goncourt, André Schwarz-Bart apresenta a gênese do Ciclo, em 1967, em diversos âmbitos: no Figaro littéraire, em conferências de imprensa, em artigos e em entrevistas. Na oportunidade, ele anuncia um projeto de enorme fôlego, com volumes claramente delineados, a ser empreendido em mais de dez anos de intenso fazer literário. No que tange ao protagonismo de Solitude e sua genealogia, Simone Schwarz-Bart preconiza que,

Como em todo o mundo, as pessoas simplesmente precisam de mitos fundadores e, sobretudo, de heróis aos quais possam se identificar. Uma mulher como a mulata Solitude é um ícone. Nossos escritos experimentam o desejo e a vontade de compor uma galeria de retratos que serve de espelho aos que querem (Le Gros, 2015).

Certamente, o Ciclo antilhano "é um zoom, com o ângulo mais largo possível, sobre nós mesmos, descendentes de escravos. Quanto mais tivermos exemplos, mais aumentaremos nossa família que é grande" (Le Gros, 2015).

versão, a imagem de Solitude se mostra estilizada, apenas com os contornos do corpo feminino. Em setembro de 2020, Anne Fidalgo, prefeita de Paris, inaugurou o Jardin Solitude na Praça do Général-Catroux, na capital francesa e anunciou o projeto de uma estátua em homenagem à guadalupense. Caso o projeto se concretize, a estátua retratará a primeira mulher negra a ser imortalizada em Paris e a quadragésima mulher em meio a mais de mil estátuas que compõe o acervo patrimonial parisiense. A obra de André Schwarz-Bart, de 1972, inaugura o protagonismo de Solitude na seara literária. No âmbito teatral, Solitude inspirou uma comédia musical dirigida por Pascal Vallot em 2008. Em 2014, a UNESCO tornou pública a série on line Femmes dans I'histoire de l'Afrique [Mulheres na história da África], na qual apresenta em formato de quadrinhos a biografia da escravizada Solitude. Em 2020, foi lançada a obra Solitude, la flamboyante, escrita por Paula Anacaona, escritora e editora-chefe da Editora Anacaona. Criada em 2009, a editora faz a promoção de textos críticos e literários brasileiros em francês, dentre os quais citamos Marcelino Freire e a coleção Feminismos plurais, organizada por Djamila Ribeiro. 
O Ciclo antilhano reivindica um olhar para os ancestrais e promove uma exaltação à memória do período escravagista e um reconhecimento dos valores históricos, sociais e culturais intimamente ligados à diáspora negra no Caribe. Dedicado aos filhos do casal, o romance L'Ancêtre en Solitude apresenta Bernard e Jacques como "duas correntes da linhagem Solitude” (Schwarz-Bart, 2015c, p. 7), reiterando a reivindicação de filiação aos escravizados que compõem o mosaico identitário nas Américas. Simone explica em detalhes as diretrizes que acompanham e motivam o Ciclo e enfatiza os diferentes matizes a serem ressaltados em seu entoar: "Alguma coisa nos falta: necessidade de se reapropriar do heroísmo dos bravos, mas também dos 'quase-nada', destes lamed-vovnik, estes justos silenciados que ignoram a si mesmos. A memória coletiva precisa reinventar o passado para apropriá-lo" (2015c, p. 14). A ficção, definida como "meio superior de conhecimento" (2015c, p. 14), apresenta-se como gênero frutífero para revisitar o passado e, de alguma maneira, passá-lo a limpo.

Simone e André Schwarz-Bart escreveram a quatro mãos a obra Un plat de porc aux bananes vertes, publicada em 1967, primeiro tomo do Ciclo. Contudo, alguns anos mais tarde, em 1972, publicam obras individuais: ela inaugura uma escrita autônoma com o premiado Pluie et vent sur Télumée Miracle, e ele lança La mulâtresse Solitude. As reações melindradas aos dois romances de André Schwarz-Bart culminaram no engavetamento do projeto do Ciclo antilhano. Os diálogos literários promovidos por André entre Le Dernier des justes e La mulâtresse Solitude foram ignorados pelos críticos. Simone declara que essa última obra foi vítima de um "linchamento" (2015c, p. 12) público e confessa que ela foi responsável pela reclusão e pelo ostracismo que encerraram o marido. Frustrado, ele escrevia regularmente, mas refutava qualquer possibilidade de novas publicações. Com o falecimento do marido e parceiro literário, Simone se afasta da cena literária durante pouco mais de 25 anos. Especialista da obra de André Schwarz-Bart, Francine Kaufmann foi a grande responsável 
pela retomada do Ciclo antilhano, tendo localizado, ordenado e estudado o espólio de André após seu falecimento, em 2006. As anotações, diários, projetos, laudas e rascunhos localizados por ela promoveram a "ressurreição" (Schwarz-Bart, 2015c, p. 15) do ambicioso projeto.

A retomada do Ciclo ocorre em 2015 com o romance L'Ancêtre en Solitude, laureado com os prêmios Littérature Monde e Grand Prix du Congrès des Écrivains de la Carä̈be, no mesmo ano. Acerca dos questionamentos de o livro ser assinado pelo casal, nove anos após o falecimento de André, ela declara que "não é usual escrever com um morto. Foi um processo doloroso, mas necessário. Está na hora deste trabalho ser restituído" (Le Gros, 2015). Numa esfera mais íntima, retomar o Ciclo antilhano representa para Simone reconstruir um "nós" nas tramas ficcionais, significa retirar André do ostracismo infligido pela recepção das primeiras obras, resgatar um projeto que lhe era muito caro e reivindicar sobrevida ao Ciclo prematura e abruptamente interrompido. Reassumir a saga de Solitude consiste em negar a morte e o silenciamento e permite a retomada de uma trajetória literária que se inicia por incentivo do marido e que parece a ele atrelada.

Em entrevista concedida ao programa Bibliothèque Médecis, quando da publicação do romance, a escritora explica os anos de silêncio como ato de cumplicidade ao marido: "com a morte de André, eu continuei o silêncio porque ele estava em silêncio. [...] Nem ele nem eu [...] Há situações onde é preciso se calar" (Schwarz-Bart, 2015a). Ressalta, em seguida, o valor terapêutico da composição do Ciclo antilhano: "André me dava um mundo de memória enquanto nós, Antilhanos, nós cultivávamos o esquecimento. Juntos, nós fazíamos uma coisa muito necessária a mim mesma: iluminar minha noite e a noite dos meus" (Schwarz-Bart, 2015a).

Em 2017, o Ciclo conhece a obra Adieu Bogota e renova o fôlego retomado com L'Ancêtre en Solitude. A despeito da transformação das diretrizes iniciais e da expressiva mudança de títulos, a empreitada cor- 
robora o propósito de "mostrar ao mundo as histórias destas gerações de homens e mulheres” (Le Gros, 2015). Trata-se de

mostrá-las às novas gerações antilhanas. Nossa ambição era recolocar esses personagens em suas próprias histórias, de maneira que as novas gerações constituam os projetos, a maneira de viver, a metafísica, a sabedoria que os antigos iniciaram. Que eles possam se apoiar sobre sua própria memória. Reencontrar o fio dessa genealogia (Le Gros, 2015).

Simone Schwarz-Bart publicou obras para além do projeto do Ciclo antilhano, a saber: os romances Pluie et vent sur Télumée Miracle (1972) e Ti Jean l'horizon (1979) e a peça teatral Ton beau capitaine, de 1987. Escreveu ainda Hommage à la femme noire, enciclopédia em seis volumes e mais de 1.500 laudas que propõe um inventário de mulheres, de diferentes nacionalidades e épocas, esquecidas pela história oficial, e a novela $\mathrm{Du}$ fond des casseroles, todos em 1989. Em 2019, publicou com Yann Plougastel a obra Nous navons pas vu passer les jours, pela editora Grasset. De contornos autobiográficos e dedicada aos filhos, a narrativa foi assim apresentada pela editora:

Esta é a história de um casal raro. A de dois escritores, uma guadalupense, o outro judeu, cujas obras atestam o sofrimento de seus povos. E o de dois seres perdidamente ligados, que, durante 55 anos, todas as noites, leram juntos um poema de amor de Pablo Neruda.

Há, no entanto, um mistério em torno dos Schwarz-Bart. Por que, em meados da década de 1970, ficaram em silêncio e se trancaram em sua casa em Guadalupe? Doze anos após o desaparecimento de seu marido, Simone dá sua verdade sobre a extraordinária jornada de um pequeno judeu de origem polonesa e uma solitária mestiça. 
No mesmo ano de 2019, o casal Schwarz-Bart recebe uma belíssima homenagem do premiado e prestigiado escritor guadalupense Ernest Pépin: a obra La Souvenance, publicada pela Caraïbéditions. Definido por Loïc Céry como "narrativa biográfica romanceada, reconstituição de itinerários e de poética” (2019), o livro retraça o percurso do casal, "um dos mais marcantes da literatura mundial [...] que se eleva quase ao nível de mito" (Céry, 2019) e se apresenta como leitura complementar à obra Nous niavons pas vu passer les jours. Pépin tece seu romance a partir de um palimpsesto narrativo: o contador de histórias que acolhe referências explícitas às obras do casal, cartas ficcionais que Simone escreve ao marido e vozes de extremo lirismo, que descortinam o arquipélago de Guadalupe tão entoado nas páginas literárias de ambos.

O escritor guadalupense Daniel Maximin dedica ao casal Schwarz-Bart o poema "Case créole", no qual entoa que "apesar da solidão / poteau-mitan conecta [...] apesar da sede / poteau-mitan rejeita a chuva / apesar de todos os pesares / poteau-mitan sustenta a luz / poteau-mitan abre a roda / para nos falar" (2009, p. 23). O poema se atém à imagem do poteau-mitan, pilar de sustentação da casa crioula, localizado no centro da construção e responsável por escorar o teto. $\mathrm{Na}$ cultura religiosa do vodu, no Haiti, muitos rituais se realizam em torno desse pilar. Nas ilhas de Martinica e Guadalupe, poteau-mitan se tornou uma metáfora capaz de representar o esteio, a resistência e a força feminina na sustentabilidade da sociedade, verdadeiros patrimônios na arquitetura social antilhana. No poema, Daniel Maximin, para além de citar as chuvas e as intempéries do universo romanesco de Simone, promove uma aproximação do casal ao poteau-mitan, aludindo à força deste como expoente central da cultura crioula.

Simone Schwarz-Bart transita com desenvoltura no âmbito do romance, seu gênero de predileção. Experimentou uma única vez os caminhos da dramaturgia e, no que pese sua escrita fortemente poética, não publicou poemas. A escritora se dedica de maneira irregular 
e descontínua à escrita literária. Em 2015, retomou o impulso literário e vem publicando regularmente a cada dois anos, o que ocorreu em 2017 e 2019, após um hiato de mais de duas décadas. À Simone, foram concedidas, até o presente momento, quatro distinções literárias: em 1973, o Grand Prix des lectrices d'Elle por Pluie et vent sur Télumée Miracle; em 2008, o Prix Carbet de la Caraïbe, prêmio atribuído à Simone e à André Schwarz-Bart pelo conjunto da obra; e, em 2015, o Prix Littérature-monde e o Grand prix du Congrès des écrivains de la Caraïbe por L'Ancêtre en Solitude.

A despeito da relevância da obra de Simone Schwarz-Bart nos cenários antilhano e internacional, a escritora se mostra reservada e avessa aos protocolos, por assim dizer, dos mundos literários e editoriais. Evita participar de eventos acadêmicos e raramente é vista na companhia de demais escritores e agentes literários. Durante décadas foi proprietária de um antiquário em Pointe-à-Pitre, o “Tim, Tim”, loja que dirigia pessoalmente e que transformava com maestria em espaço de encontros, de diálogos e de cumplicidade com os clientes.

Definida pelos intelectuais martinicanos Patrick Chamoiseau e Raphaël Confiant como autora de um best-seller (Pluie et vent sur Télumée Miracle) “inesgotável” (apud Gyssels, 1999), Simone Schwarz-Bart se consolidou desde a década de 1970 como escritora vanguardista que antecipou as linhas de força artísticas sugeridas no célebre manifesto bilíngue Éloge de la créolité, escrito por Chamoiseau, Confiant e Bernabé. É mister ressaltar que o manifesto se propõe a repertoriar as artes de fazer literárias nas Antilhas, contemplando inventários temáticos e procedimentos estéticos capazes de lançar luzes sobre a crioulidade, a identidade caribenha e o enraizamento na oralidade, preconizando o plurilinguismo, a memória e o inconsciente coletivos e as práticas crioulas na cena artística caribenha.

Menções à Simone Schwarz-Bart e à suas obras podem ser repertoriadas em leituras de obras caribenhas e pós-coloniais, num palimpsesto deveras afetivo. A título de exemplificação, acolhemos inicialmente dois 
conterrâneos guadalupenses: Maryse Condé, em 2003, elenca Pluie et Vent sur Télumée Miracle como única obra lida pela personagem Rosélie (2003, p. 171), no romance Histoire de la femme cannibale, e Daniel Maximin, em Lî̀le et une nuit, de 1995, evoca o título do romance ao descrever a fúria de um ciclone que se aproxima (1995, p. 35).

No ensaio Les fruits du cyclone (2006), Maximin faz pelo menos duas menções à Simone Schwarz-Bart e à obra Pluie et vent sur Télumée Miracle. No início do segundo capítulo, o autor associa o texto de Simone ao conceito de poteau-mitan, fazendo alusão à resiliência da protagonista swarz-bartiana diante das intempéries do cotidiano, como já mencionamos. Na parte final do ensaio, Maximin retoma a autora para ilustrar a tese de que o engajamento do artista reside em "recusar-se a ser prisioneiro da história de sua prisão, e, com sua parcela de liberdade, de imaginação, testemunhar para estas comunidades originais, e mostrar que podemos, como indicava o poema: construir para nós uma dignidade" (2006, p. 216-217). Em seguida, o ensaísta acolhe os parágrafos iniciais da obra-prima de Simone Schwarz-Bart para versar acerca da vitória diante da origem perdida e da recriação da terra de acolhimento a partir da emigração forçada. Com a exaltação da Guadalupe entoada na tessitura romanesca da autora, Daniel Maximin encerra seu ensaio sob o premissa do desafio de enraizamento e da mistura de "seiva e de sangue " (2006, p. 218) que acompanharam a formação identitária antilhana nesta terra de "transplantados" (GLISSANT, 2012, p. 175) onde se reconhecem muitas "depossessões" (GLISSANT, 2012, p. 95).

Alain Mabanckou, autor congolês, brinca em Verre Cassé (Copo quebrado, em tradução brasileira de Paula Souza Dias Nogueira, em 2018) com o romance de estreia de Simone na sentença "como se na véspera tivesse comido um prato de porco com bananas verdes" (2005, p. 114).

Por fim, a guadalupense Dominique Deblaine faz reiteradas menções à Simone Schwarz-Bart na obra Paroles d'une île vagabonde (2011), na qual promove um tessitura de citações de obras guadalupenses iniciada por Pluie et vent sur Télumée Miracle (2011, p. 66). Na 
esteira de Daniel Maximin, encerra a obra póetica com um inventário de títulos da matriarca antilhana e com a confissão de que "como eles, estou lá, em pé no vento que conhece minha resistência" (2011, p. 107).

O martinicano Patrick Chamoiseau acolhe Simone Schwarz-Bart no panteão de sua sentimenthèque, biblioteca sentimental por ele apresentada na obra Écrire en pays dominé (1997). Em sua homenagem- citação, Chamoiseau faz referência à luta da autora contra a "aniquilação" (2011, p. 198) e pelo desejo de seguir "o fio das vidas como se embarcasse num sonho" (2011, p. 198).

Em entrevista concedida à Thomas C. Spear em 2010 e publicada três anos mais tarde na incontornável plataforma de cultura francófona insular Île en île, Simone Schwarz-Bart revelou sua compreensão a propósito de sua "obra", o que corrobora sua humildade artística e seu distanciamento dos círculos literários:

O que você chama de 'Obra' só existe aos olhos do público. Para mim, esses são apenas alguns dos momentos da minha vida que congelam ao longo do tempo em uma espécie de currículo onde às vezes acho difícil me reconhecer. Acredito na espontaneidade, e acredito que ela só se move no escuro. Não é só o significado do meu 'trabalho' que me escapa. É também o significado da minha vida, esse sentido do que é mais essencial na minha vida: e eu me certifico cuidadosamente de que é assim, pois essa escuridão é para mim a verdade.

Simone Schwarz-Bart mora na comuna de Goyave, na Basse-Terre, no arquipélago antilhano de Guadalupe, e passa anualmente temporadas em Paris. Goyave, é preciso que se diga, imprime-se na tessitura literária da autora, como ela explica:

Goyave é a única em Guadalupe a ter o nome de uma fruta. O lugar permaneceu intocado pelos vírus que inevitavelmente levam ao progresso. É uma terra de mar, montanhas, rios. A 
floresta permanece em grande parte o domínio das rastas que colocaram suas caixas na folhagem como ninhos de pássaros. Seus móveis deixariam muitos designers de móveis pálidos e eles vivem lá a partir dos frutos de seus jardins. Eles guardam com ciúmes essas florestas e seu estilo de vida os coloca como guardiões dessa natureza. Os rios são onipresentes em Goyave e a 'Bacia Azul' é minha piscina favorita, uma pequena safira instalada na junção de dois rios que se fundem neste momento. Meus personagens vêm desse espaço de mar e floresta, sussurrando com água branca borbulhante e cantando antes de se perder no oceano e seu abismo. Conheço a história deles, sei que eles se multiplicam com prazer em uma oralidade rica, verde e livre que lhes abre o sonho, sua vida dos sonhos, permitindo-lhes sustentar a dureza da realidade (2013). 